\title{
The efficacy and safety of add-on $0.1 \%$ brimonidine tartrate preserved with sodium chlorite in on-treatment Japanese normal-tension glaucoma patients
}

This article was published in the following Dove Press journal:

Clinical Ophthalmology

I September 2014

Number of times this article has been viewed

\author{
Toyoaki Tsumura' \\ Keiji Yoshikawa ${ }^{2}$ \\ Tairo Kimura ${ }^{3}$ \\ Hirotaka Suzumura ${ }^{4}$ \\ Miwako Kawashima ${ }^{5}$ \\ Mami Nanno ${ }^{6}$ \\ Kiyotaka Ishijima ${ }^{7}$ \\ Ryuji Takeda ${ }^{8}$ \\ 'Fussa Hospital, Tokyo, Japan; \\ ${ }^{2}$ Yoshikawa Eye Clinic, Tokyo, Japan; \\ ${ }^{3}$ Ueno Eye Clinic, Tokyo, Japan; \\ ${ }^{4}$ Suzumura Eye Clinic, Tokyo, Japan; \\ ${ }^{5}$ Nakano General Hospital, Tokyo, \\ Japan; ${ }^{6}$ Kagurazaka Minamino Eye \\ Clinic, Tokyo, Japan; ${ }^{7}$ Irumagawa \\ Hospital, Saitama, Japan; ${ }^{8}$ Department \\ of Biological Chemistry, Faculty \\ of Agriculture, Kinki University, \\ Nara, Japan
}

Correspondence: Toyoaki Tsumura Fussa Hospital, I-6-I Kamidaira, Fussa, Tokyo I97-85II, Japan

Tel +8 I 4255 I I III

Fax +8I 425516112

Email tsumura@fussahsp.jp
Background: To evaluate the efficacy and safety of newly formulated brimonidine $(0.1 \%$ brimonidine tartrate preserved with sodium chlorite: brimonidine) as add-on therapy in on-treatment Japanese normal-tension glaucoma (NTG) patients.

Methods: Brimonidine was added to on-treatment NTG patients with intraocular pressures (IOP) of between $13 \mathrm{mmHg}$ and $16 \mathrm{mmHg}$ after three consecutive IOP measurements. The time courses of IOP, conjunctival hyperemia, superficial punctate keratitis, and adverse events were examined at 4,8 , and 12 weeks after brimonidine instillation.

Results: Though 75 of 83 patients ( 31 males and 52 females; mean age: $63.4 \pm 11.6$ years) completed the study, six patients discontinued because of side effects and two patients withdrew. The mean IOP after brimonidine addition at week $4(12.6 \pm 1.8 \mathrm{mmHg}, P<0.001)$, week 8 (12.4 $\pm 1.7 \mathrm{mmHg}, P<0.001)$, and week $12(12.6 \pm 1.8 \mathrm{mmHg}, P<0.001)$ was significantly decreased compared with that before the addition of brimonidine $(13.9 \pm 1.2 \mathrm{mmHg})$. No significant changes in superficial punctate keratitis or conjunctival hyperemia scores were observed throughout the study. Dizziness, sleepiness, eye pain, and itching (mild to moderate) were noted in five, four, three, and three patients, respectively.

Conclusions: The addition of newly formulated brimonidine to on-treatment Japanese NTG patients with IOP of 13-16 mmHg further reduced the levels of IOP with minimal side effects and adverse events.

Keywords: normal-tension glaucoma, $0.1 \%$ brimonidine tartrate with sodium chlorite, additive intraocular pressure reduction, side effect, adverse event

\section{Introduction}

Normal-tension glaucoma (NTG) is the most common type of glaucoma in Japanese individuals. ${ }^{1,2}$ Although monotherapy with prostaglandin (PG) analogs is mainly applied as the first-line treatment for NTG, ${ }^{3,4}$ additional treatment with second-line glaucoma ophthalmic solutions is frequently needed, as the target intraocular pressure (IOP) for NTG is relatively low compared with that in primary open-angle glaucoma (POAG). ${ }^{5}$

Brimonidine, an $\alpha_{2}$-adrenergic agonist, is postulated to be clinically useful for glaucoma treatment, in particular for add-on therapy, because it has a unique IOPlowering mechanism of action. ${ }^{6}$

The concentration of brimonidine in ophthalmic solution was decreased from $0.2 \%$ to $0.1 \%$, and the preservative was reformulated from benzalkonium chloride (BAK) 
to sodium chlorite (SC) in an effort to enhance tolerability in brimonidine usage. ${ }^{7}$ At present, this new formulation of brimonidine $(0.1 \%$ brimonidine tartrate ophthalmic solution with SC: Aiphagan ${ }^{\circledR}$; Senju Pharmaceutical Co., Ltd, Osaka, Japan) has been marketed in Japan since 2012.

To the best of the authors' knowledge, however, previous studies of the efficacy and safety of brimonidine in NTG treatment evaluated $0.2 \%$ brimonidine with BAK. ${ }^{8,9}$ No study has been conducted for the treatment of NTG using $0.1 \%$ brimonidine with SC. ${ }^{10}$

We therefore evaluated the IOP-lowering efficacy and safety of newly formulated $0.1 \%$ brimonidine preserved with SC as an add-on therapy in on-treatment Japanese NTG patients with IOP of $13-16 \mathrm{mmHg}$.

\section{Materials and methods Study design}

This prospective, open-label, multicenter study was conducted over a period of 12 weeks at Fussa Hospital, Yoshikawa Eye Clinic, Ueno Eye Clinic, Nakano General Hospital, Kagurazaka Minamino Eye Clinic, and Irumagawa Hospital in Japan from June 2012 to January 2013. The study was carried out according to the ethical principles of the Declaration of Helsinki. All patients read and signed an informed consent form, and the Institutional Review Board of Fussa Hospital approved the study in advance. This study was registered in the University Hospital Medical Information Network (UMIN) clinical trials registry (No UMIN000012582).

\section{Participants}

Japanese NTG patients diagnosed according to Japanese glaucoma guidelines 5 and receiving one to three drugs including PG, without a change of prescription for 3 months, were recruited.

Inclusion criteria for enrolled patients were as follows: $1)$ aged $\geq 20$ years and $\leq 80$ years who were diagnosed with NTG in both eyes; 2) patients undergoing treatment with PG and/or $\beta$-blockers who were judged to require the addition of brimonidine because they were unable to achieve target IOP on their current IOP-lowering therapy; 3) on-treatment IOPs in bilateral eyes of between $13 \mathrm{mmHg}$ and $16 \mathrm{mmHg}$ in at least three consecutive measurements; 4) patients with an IOP of 10-12 mmHg were eligible if the central corneal thickness was $\leq 470 \mu \mathrm{m} ; 5$ ) mean deviation (MD) values $<-6 \mathrm{~dB}$ using the Humphrey central 30-2/24-2 Swedish Interactive Threshold Algorithm standard program (Carl Zeiss Meditec Inc., Dublin, CA, US), or any patients with central visual field loss (Figure 1); 6) best-corrected visual acuity $\geq 0.5$; and (7) spherical equivalent refraction $\geq-10 \mathrm{D}$.

Exclusion criteria were as follows: 1) abnormalities of the anterior segment that disturbed accurate IOP measurement with the Goldmann applanation tonometer; 2) apparent findings of dry eye; 3) any active ocular inflammation or blepharitis; 4) a history of laser therapy or surgical treatment of glaucoma; 5) patients requiring treatment with steroid eye drops during the study; 6) patients who had ocular fundus diseases that may affect visual field; and 7) patients judged ineligible by an investigator.

\section{Procedure}

One drop of brimonidine was added to instil into the bilateral conjunctival sac twice a day for 12 weeks at the predefined time (12-hour intervals) for each patient. Measurements of IOP, best-corrected visual acuity, slit-lamp examinations, and interviews for adverse events were conducted in each clinic at 4,8 , and 12 weeks after the addition of brimonidine.

IOP was measured twice consecutively between 9 am and 1 pm by a single examiner using a Goldmann applanation tonometer. The mean of the two IOP measurements at each time point was calculated and used for statistical analyses.

The degrees of conjunctival hyperemia and superficial punctate keratitis (SPK) were scored from 0 to 3 and 0 to 4 based on the standard photogram, respectively. ${ }^{11-13}$ For evaluation of adverse events, patients were examined with a slit lamp for the presence or absence of red eyelid, eyelid edema, conjunctival edema, and conjunctival follicles.

Each adverse event, such as ocular irritation, itching and foreign body sensation, and/or dry eye sensation, was classified into four grades: "nothing", "almost nothing", "sometimes" and "always". Patients were interviewed at each visit to confirm their experiences of dizziness or sleepiness.

Blood pressure and pulse rate were measured for each patient at the start and end of the study. MD values were compared before and after the study.

\section{Statistical analysis}

All data collected from patients who fulfilled all of the inclusion criteria and did not meet any of the exclusion criteria were sent to Kinki University, Nara, Japan, and were analyzed by a statistician who did not directly collect data in the clinical study.

In each patient, one eye with a higher on-treatment IOP before the addition of brimonidine (the study eye) was used for statistical analysis. If both eyes had the same IOP values, 
(1) Patients with $\mathrm{C} 30-2 / \mathrm{C} 24-2 \mathrm{MD}<-6.0 \mathrm{~dB}$

(2) Patients who have $\mathrm{C} 30-2 / \mathrm{C} 24-2 \mathrm{MD} \geq-6.0 \mathrm{~dB}$ and meet either criteria A or B below:

A

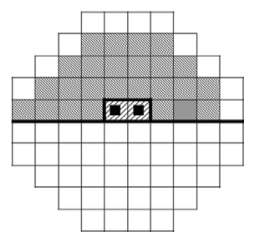

2 of the 4 central adjacent points on C30-2/C24-2 grid have

$P<0.5 \%$ (except 2 vertically or diagonally adjacent points).

B

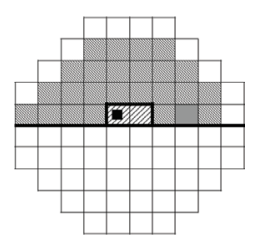

i) At least 3 adjacent or non-adjacent points in the row above or below the horizontal meridian on $\mathrm{C} 10-2$ grid have $P<1 \%$.
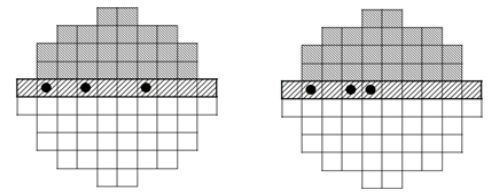

ii) At least 15 points in either the upper or the lower hemifield (34 points) on C10-2 grid have $P<1 \%$.
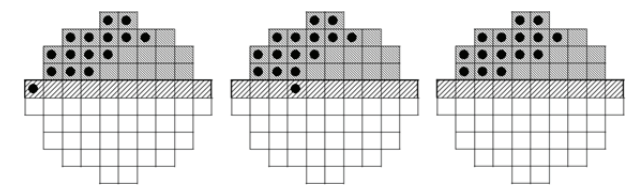

Figure I Visual field criteria required for patients' inclusion in the study.

Note: C30-2/24-2, C10-2: The Humphrey central 30-2/24-2 or 10-2 Swedish Interactive Threshold Algorithm standard program.

Abbreviations: $\mathrm{dB}$, decibel; $\mathrm{MD}$, mean deviation.

the eye with the lower MD value served as the study eye. ${ }^{14}$ In patients with the same IOP values and MD values in both eyes, the right eye was selected. IOPs obtained before and after add-on with brimonidine in the patients who were able to be followed up for at least 4 weeks were used in the analysis using a paired $t$-test with Bonferroni correction after repeated analysis of variance.

The relationship between the magnitude of IOP reduction in those eyes that were followed for up to 12 weeks, baseline characteristics, and the number of pretreated drugs was analyzed by multivariable logistic regression analysis.

Scores of conjunctival hyperemia and SPK in the study eyes were examined using a Wilcoxon signed rank test. Cumulative incidences of adverse events such as conjunctival and eyelid findings were calculated and statistically tested by a chi-square test. Blood pressures, pulse rates, and MD values before and after treatment with brimonidine were compared using a paired $t$-test. For statistical analysis, JMP ${ }^{\circledR}$ software (version 9.0.2; SAS Institute Inc., Cary, NC, USA) was used. $P$-values $<0.05$ were considered to be significant.

\section{Results}

A total of 75 out of 83 enrolled patients ( 31 males and 52 females; mean age: $63.4 \pm 11.6$ years) completed the study (Table 1). Eight patients did not complete the study due to dropping out (two patients) and adverse events (six patients; dizziness: three, sleepiness: one, eye pain: one, eye itching: one).

Compared with the IOPs before the addition of brimonidine, the IOPs in the study eyes showed a significant reduction at each time point $(P<0.001)$ (Figure 2). At 12 weeks, the IOP was lowered by $0-1 \mathrm{mmHg}$ in 33 patients $(44.0 \%)$, 2-3 $\mathrm{mmHg}$ in 25 patients (33.3\%), and $\geq 4 \mathrm{mmHg}$ in seven patients $(9.3 \%)$. A $2 \mathrm{mmHg}$ or greater reduction was observed

Table I Demographic characteristics of the study participants

\begin{tabular}{|c|c|}
\hline Number of patients & 83 \\
\hline Male/female & $31 / 52$ \\
\hline Eyes (R/L) & $83(40 / 43)$ \\
\hline Age $\left(\right.$ years) ${ }^{a}$ & 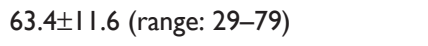 \\
\hline $\mathrm{RE}(\mathrm{D})^{\mathrm{a}}$ & $-2.97 \pm 3.06$ (range: -10.00 to +2.5$)$ \\
\hline $\mathrm{MD}(\mathrm{dB})^{\mathrm{a}}$ & $-10.72 \pm 4.63$ (range: -19.90 to -1.59$)$ \\
\hline $\mathrm{CCT}(\mu \mathrm{m})^{\mathrm{a}}$ & $520.6 \pm 35.9$ (range: $446-6 \mid 4)$ \\
\hline Number of previous & $2.0 \pm 0.8$ \\
\hline \multirow[t]{5}{*}{ antiglaucoma drugs } & I drug: 29 (PG: 27, $\beta$-blocker: 2) \\
\hline & 2 drugs: 27 (PG + $\beta$-blocker: 15, \\
\hline & PG + CAI: II, PG + others: I) \\
\hline & 3 drugs: 27 (PG + $\beta$-blocker + CAl: \\
\hline & 26, PG + CAI + others: I) \\
\hline
\end{tabular}

Note: ${ }^{\text {a }}$ alue is presented as the mean \pm standard deviation.

Abbreviations: CAI, carbonic anhydrase inhibitor; CCT, central corneal thickness; $\mathrm{D}$, diopter; dB, decibel; L, left; MD, mean deviation; PG, prostaglandin; R, right; RE, refractive error. 


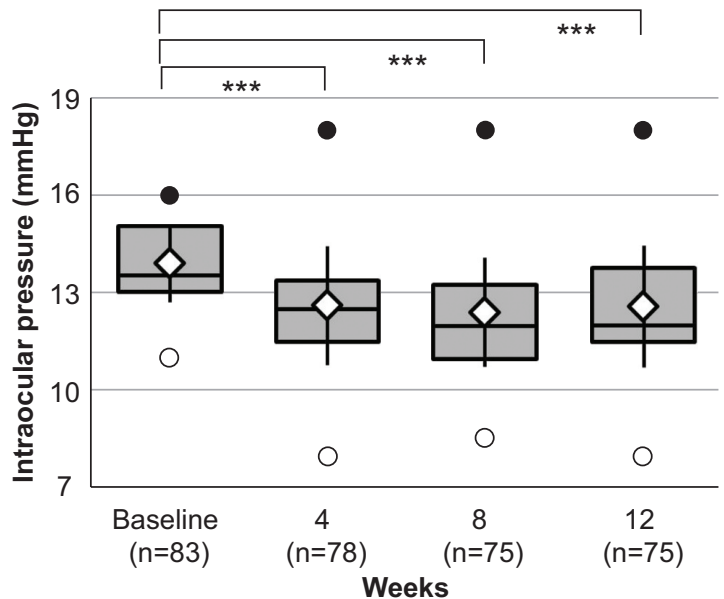

Figure 2 Intraocular pressure values in time course. ${ }^{a}$

Notes: ${ }^{a}$ The top of the box represents the 75th percentile, the bottom of the box represents the 25 th percentile, and the horizontal line in the box represents the median. $\checkmark$ denotes the mean \pm standard deviation, $\cdot$ denotes the maximum, and $O$ denotes the minimum. $* * * P<0.0001$, analyzed by paired $t$-test with Bonferroni correction after repeated analysis of variance.

Abbreviation: $\mathrm{n}$, number of eyes.

in 32 of 75 eyes (42.7\%). Brimonidine significantly lowered IOP compared with preaddition, regardless of the number of previous antiglaucoma drugs (Figure 3).

The correlation between various factors, including demographic characteristics, and the change from on-treatment IOP before the addition of brimonidine were analyzed using logistic regression analysis, and the magnitude of IOP reduction at 12 weeks significantly correlated with MD value and degree of refraction (Table 2).

Scores of conjunctival hyperemia in the study eyes were not significantly increased at each time point (Table 3). No significant differences in the SPK scores were observed at any time point in the study eyes (Table 3). Conjunctival edema, conjunctival follicles, reddish eyelid, and eyelid edema

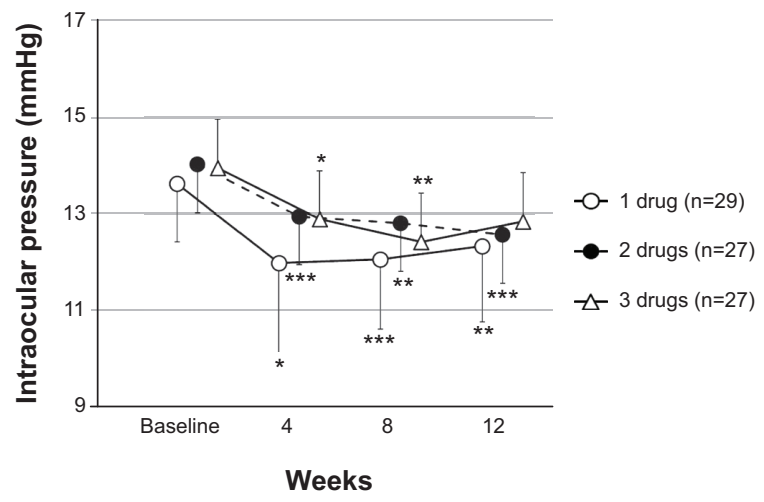

Figure 3 Change of intraocular pressure (IOP) in three groups with previous antiglaucoma drug administration. ${ }^{\mathrm{a}}$

Notes: ${ }^{\mathrm{a} E y e s}$ were classified into three groups based on the number of previous drugs. $* P<0.05$, $* * P<0.01$, $* * * P<0.000$ I for significant change of IOP compared with each baseline by repeated-measures analysis of variance with Bonferroni correction.
Table 2 Logistic regression analysis of 12 weeks IOP changes from on-treatment IOP before addition of brimonidine

\begin{tabular}{lll}
\hline Factor & Odds ratio & $P$-value (likelihood ratio test) \\
\hline Baseline IOP & 0.59 & 0.1071 \\
Number of drugs & 1.61 & 0.8106 \\
MD value & 0.84 & 0.02 \\
Age & 1.04 & 0.1328 \\
Sex & 1.75 & 0.3677 \\
RE & 20.8 & 0.0407
\end{tabular}

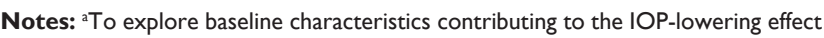
of brimonidine, subjects were divided into those experiencing an IOP reduction of $\geq 2 \mathrm{mmHg}$ and those experiencing an IOP reduction of $<2 \mathrm{mmHg}$, and a multivariate logistic regression analysis was performed to calculate odds ratios.

Abbreviations: IOP, intraocular pressure; MD, mean deviation; RE, refractive error.

were observed in $1.2 \%, 4.8 \%, 2.4 \%$, and $1.2 \%$ of patients, respectively, but no significant increase in frequency of these side effects was observed during the follow-up period (Figure 4). There were no significant changes in the cumulative incidence of adverse events over time (irritation, itching, foreign body sensation, and dry eye sensation) $(P=0.6561$, $P=0.8270, P=0.7932, P=0.8803$; Figure 5).

No apparent changes were observed in systolic and diastolic blood pressure $(130.4 \pm 18.2 \mathrm{mmHg}, 80.5 \pm 12.7 \mathrm{mmHg}$, $130.1 \pm 19.2 \mathrm{mmHg}, 79.9 \pm 14.5 \mathrm{mmHg}, P=0.6849, P=0.4692$ ) or pulse rate $(69.2 \pm 9.2 \mathrm{bpm}$ and $70.3 \pm 9.2 \mathrm{bpm}, P=0.1685)$ before or after add-on treatment with brimonidine.

Adverse events such as dizziness (five cases, 6.0\%), sleepiness (four cases, $4.8 \%$ ), eye pain (three cases, $3.6 \%$ ), and itching (mild to moderate) (three cases, 3.6\%) were observed in 15 of 83 cases (18.1\%) during the study. There was no significant difference in MD values between before and after brimonidine instillation $(10.72 \pm 4.63 \mathrm{~dB}$ and $-12.01 \pm 4.94 \mathrm{~dB}, P=0.9461$ ).

\section{Discussion}

Additive treatment with newly formulated brimonidine provided further IOP-lowering effects in Japanese NTG patients with on-treatment IOP between $13 \mathrm{mmHg}$ and $16 \mathrm{mmHg}$ who had been treated with one to three glaucoma eye drops,

Table 3 Time course of conjunctival hyperemia and superficial punctate keratitis (SPK) scores ${ }^{\mathrm{a}}$

\begin{tabular}{lllll}
\hline & Baseline & $\mathbf{4}$ weeks & $\mathbf{8}$ weeks & 1 2 weeks \\
\hline $\begin{array}{l}\text { Conjunctival } \\
\text { hyperemia scores }\end{array}$ & $0.5 \pm 0.7$ & $0.5 \pm 0.7$ & $0.5 \pm 0.7$ & $0.5 \pm 0.7$ \\
$P$-value & & 0.2658 & 0.1607 & 0.1258 \\
SPK scores & $0.2 \pm 0.3$ & $0.1 \pm 0.3$ & $0.2 \pm 0.3$ & $0.2 \pm 0.3$ \\
$P$-value & & 0.1006 & 0.912 & 0.8778 \\
\hline
\end{tabular}

Notes: ${ }^{2} S c o r e s$ are presented as the mean \pm standard deviation: analyzed by Wilcoxon signed rank test. 


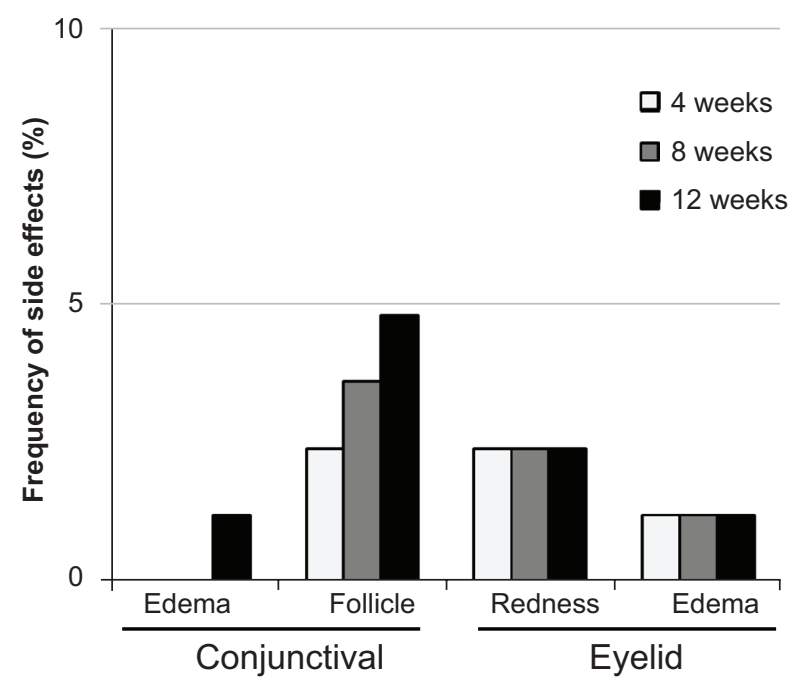

Figure 4 Side effects of conjunctiva and of eyelid in study eyes.

without serious local and systemic side effects or adverse events leading to discontinuation of administration.

As the main purpose of the present study was to examine the additive IOP-lowering efficacy of brimonidine in ontreatment Japanese NTG patients under a multicenter study design, inclusion criteria were strictly defined in respect of IOP levels and the visual field condition of the study candidates. Therefore, only those patients with on-treatment IOP between $13 \mathrm{mmHg}$ and $16 \mathrm{mmHg}$ were included, as IOP levels of $\leq 12 \mathrm{mmHg}$ are generally considered not to need further IOP lowering, ${ }^{15}$ whereas those patients with on-treatment IOP of $\geq 17 \mathrm{mmHg}$ might need to undergo surgery or laser therapy. ${ }^{5}$ The thickness of the cornea may affect the IOP measurement; ${ }^{5,16}$ however, patients with on-treatment IOP of $10-12 \mathrm{mmHg}$ were eligible if the central corneal thickness was $\leq 470 \mu \mathrm{m}$. Regarding the grade of visual field defects, the necessity of add-on therapy for patients with mild visual

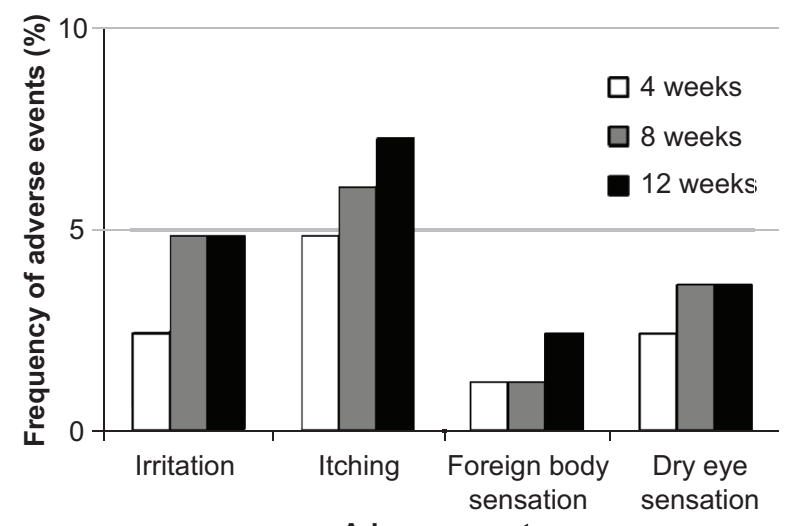

Adverse events

Figure $\mathbf{5}$ Adverse events experienced in study eyes. field loss is thought to be low. Therefore, patients with an MD value $<-6 \mathrm{D}$ who were thought to have moderate visual field loss were recruited as study subjects. On the other hand, patients with central visual field defects, as shown by the Swedish Interactive Threshold Algorithm standard program (C10-2) visual field test, who met the new criteria provided in Figure 1 were enrolled because such defects may cause a threat to vision and such patients are thought to need further IOP lowering. ${ }^{17}$ Patients with severe myopia $(<-10 \mathrm{D})$ were excluded from the study because myopic optic neuropathy may be confused with glaucoma.

Although the speed of progression of visual field loss in $\mathrm{NTG}^{18}$ is recognized to be slower than that in POAG, it inevitably progresses. Therefore, IOP-lowering therapy is required for NTG, as it is with POAG. In the treatment of NTG, a decrease in IOP of around 20\% from baseline was generally achieved by applying PG analogs as monotherapy. ${ }^{19}$ However, in those cases with visual field loss progression, additive treatment is required, ${ }^{20-22}$ and a proportion of NTG patients receive multiple antiglaucoma drugs. The magnitude of IOP reduction observed in the present study was $1.3 \mathrm{mmHg}$, a $9.4 \%$ reduction from preaddition of brimonidine in on-treatment NTG with IOP of 13-16 mmHg. The IOP reduction of $1 \mathrm{mmHg}$, despite being small in amount, is reported to be valuable for slowing down visual field loss, as shown in POAG in the Early Manifest Glaucoma Trial (EMGT) study ${ }^{23}$ It is considered that IOP lowering of $1.3 \mathrm{mmHg}$ is clinically relevant in NTG.

The IOP-lowering effects of brimonidine are suspected to have individual differences, as the magnitude of IOP reduction at 12 weeks was widely distributed, with $44.0 \%$ of patients having IOP lowered by $0-1 \mathrm{mmHg}$, and $42.7 \%$ lowered by $\geq 2 \mathrm{mmHg}$, including $9.3 \%$ of patients by $\geq 4 \mathrm{mmHg}$. Therefore, we tried to identify potential factors contributing to IOP reduction. The baseline IOP in patients was relatively low and the additive mean IOP-lowering efficacy was $1.3 \mathrm{mmHg}$. We selected a logistic regression for this analysis. A cutoff value of $2 \mathrm{mmHg}$ in IOP reduction should be used considering IOP measurement fluctuation of $\pm 1 \mathrm{mmHg}$. The results of the present analysis suggest that IOP in patients with nonmyopia and better MD values would be further lowered by brimonidine.

Brimonidine is known to lower IOP by reducing aqueous humor formation and increasing uveoscleral outflow. ${ }^{6}$ It is known that myopic eyes are structurally elongated while having mechanically weakened ciliary muscles. ${ }^{24}$ These changes in myopic eyes might alter the IOP-lowering effect of brimonidine. 
Addition of brimonidine was statistically prominent in patients with worse MD value. The actual time period in which patients had received glaucoma treatment could not be confirmed. However, patients with severe visual field defect, ie, worse MD value, in general, used eye drops for a longer period of time. Although no significant difference in IOP-lowering efficacy was observed based on the number of pretreated drugs, it can be postulated that patients with severe NTG might have already reached a sufficient level of pretreatment efficacy.

Significant local side effects were not observed during the 3 months of brimonidine add-on therapy. Moreover, no exacerbation of SPK or hyperemia was noted, which might be attributable to the exclusion of patients with severe dry eye from the study. In the present study we evaluated the efficacy and safety of newly formulated brimonidine, which had a decreased concentration of brimonidine and a changed preservative with less irritation. Therefore, another possible factor contributing to this favorable safety profile was the presence of $\mathrm{SC}$ in the brimonidine formulation as a nonBAK preservative, which may have the potential to reduce corneal disorders. ${ }^{25-27}$

The literature indicates that brimonidine therapy is associated with an increased risk of allergic reactions. ${ }^{28}$ Patients in this study were therefore carefully monitored in combination with subjective symptoms and slit-lamp evaluation. However, a marked increase in allergic reactions was not evident in our 3-month study. A longer follow-up study may be warranted for evaluation of these findings.

During this study, blood pressure and pulse rate did not change after brimonidine add-on, as reported in the US. ${ }^{28}$ However, some patients experienced dizziness and sleepiness. Brimonidine may lead to dizziness or sleepiness like other $\alpha_{2}$-adrenergic receptor agonists such as clonidine and apraclonidine, which can penetrate the blood-brain barrier. ${ }^{29,30}$ Therefore, before starting brimonidine therapy, patients should be informed about the risks of dizziness and sleepiness. ${ }^{31}$

\section{Conclusion}

The results of this study suggest that the addition of newly formulated brimonidine effectively lowered IOP in Japanese NTG patients with IOP of 13-16 mmHg, with minimal clinically significant side effects or adverse events. Therefore, brimonidine is thought to be useful as an add-on therapy for on-treatment NTG.

\section{Acknowledgment}

The authors thank David P Figgitt of Content Ed Net for reviewing the manuscript.

\section{Disclosure}

This study was performed without support from any associations or companies, and none of the authors has any conflicts of interest associated with this study.

\section{References}

1. Iwase A, Suzuki Y, Araie M, et al. The prevalence of primary openangle glaucoma in Japanese: the Tajimi Study. Ophthalmology. 2004; 111(9):1641-1648.

2. Yamamoto T, Iwase A, Araie M, et al. The Tajimi Study report 2: prevalence of primary angle closure and secondary glaucoma in a Japanese population. Ophthalmology. 2005;112(10):1661-1669.

3. Collaborative Normal Tension Glaucoma Study Group. The effectiveness of intraocular pressure reduction in the treatment of normal-tension glaucoma. Am J Ophthalmol. 1998;126(4):498-505.

4. Koseki N, Araie M, Tomidokoro A, et al. A placebo-controlled 3-year study of a calcium blocker on visual field and ocular circulation in glaucoma with low-normal pressure. Ophthalmology. 2008;115(11): 2049-2057.

5. [The Japan glaucoma society guidelines for glaucoma (third edition)]. Nippon Ganka Gakkai Zasshi. 2012;116(1):3-46. Japanese.

6. Arthur S, Cantor LB. Update on the role of alpha-agonists in glaucoma management. Exp Eye Res. 2011;93(3):271-283.

7. Cantor LB. Brimonidine in the treatment of glaucoma and ocular hypertension. Ther Clin Risk Manag. 2006;2(4):337-346.

8. Liu CL. Changes in intraocular pressure and ocular perfusion pressure after latanoprost $0.005 \%$ or brimonidine tartrate $0.2 \%$ in normal-tension glaucoma patients. Ophthalmology. 2002;109(12):2241-2247.

9. Cheng JW, Cai JP, Wei RL. Meta-analysis of medical intervention for normal tension glaucoma. Ophthalmology. 2009;116(7):1243-1249.

10. Day DG, Hollander DA. Brimonidine purite $0.1 \%$ versus brinzolamide $1 \%$ as adjunctive therapy to latanoprost in patients with glaucoma or ocular hypertension. Curr Med Res Opin. 2008;24(5):1435-1442.

11. Nakano T, Yoshikawa K, Kimura T, Suzumura H, Nanno M, Noro T. Efficacy and safety of tafluprost in normal-tension glaucoma with intraocular pressure of $16 \mathrm{mmHg}$ or less. Jpn J Ophthalmol. 2011;55(6): 605-613.

12. Lemp MA. Report of the National Eye Institute/industry workshop on clinical trials in dry eyes. CLAO J. 1995;21(4):221-232.

13. Yamazaki S, Nanno M, Kimura T, Suzumura H, Yoshikawa K. Effects of switching to SofZia-preserved travoprost in patients who presented with superficial punctate keratopathy while under treatment with latanoprost. Jpn J Ophthalmol. 2010;54(1):7-14.

14. Tomita G, Araie M, Kitazawa Y, Tsukahara S. A three-year prospective, randomized and open comparison between latanoprost and timolol in Japanese normal-tension glaucoma patients. Eye (Lond). 2004;18(10): 984-989.

15. Iwata K. [Primary open angle glaucoma and low tension glaucoma: pathogenesis and mechanism of optic nerve damage]. Nihon Ganka Gakkai Zasshi. 1992;96(12):1501-1531. Japanese.

16. Ehlers N, Bramsen T, Sperling S. Applanation tonometry and central corneal thickness. Acta Ophthalmol (Copenh). 1975;53(1):34-43.

17. Traynis I, De Moraes CG, Raza AS, Liebmann JM, Ritch R, Hood DC. Prevalence and nature of early glaucomatous defects in the central $10^{\circ}$ of the visual field. JAMA Ophthalmol. 2014;132(3):291-297.

18. Kim M, Kim DM, Park KH, Kim TW, Jeoung JW, Kim SH. Intraocular pressure reduction with topical medications and progression of normaltension glaucoma: a 12-year mean follow-up study. Acta Ophthalmol. 2013;91(4):e270-e275.

19. Tsumura T, Yoshikawa K, Suzumura H, et al. Bimatoprost ophthalmic solution $0.03 \%$ lowered intraocular pressure of normal-tension glaucoma with minimal adverse events. Clin Ophthalmol. 2012;6:1547-1552.

20. Kokuzawa A, Kondo Y, Yamamoto T. [Current status of medication for glaucoma in a university hospital]. Rinsho Ganka (Jpn J Clin Ophthalmol). 2006;60(9):1679-1684. Japanese. 
21. Nakai Y, Inoue K, Moriyama R, Wakakura M, Inoue J, Tomita G. [Current status of glaucoma therapy at private practices and a private ophthalmology hospital]. Atarashii Ganka (Journal of the Eye). 2008; 25(11):1581-1585. Japanese.

22. Inoue K, Shiokawa M, Okayama R, Soeda S, Hori S, Tomita G. Current status of the pattern of medication in 2012: difference between elder glaucoma patients and younger or middle aged glaucoma patients. Ganka Rinsho Kiyou. 2013;6(11):869-874. Japanese.

23. Leske MC, Heijl A, Hussein M, et al. Factors for glaucoma progression and the effect of treatment: the early manifest glaucoma trial. Arch Ophthalmol. 2003;121(1):48-56.

24. Tokoro T. [Mechanism of axial elongation and chorioretinal atrophy in high myopia]. Nihon Ganka Gakkai Zasshi. 1994;98(12):1213-1237. Japanese.

25. Katz LJ. Twelve-month evaluation of brimonidine-purite versus brimonidine in patients with glaucoma or ocular hypertension. J Glaucoma. 2002;11(2):119-126.
26. Wada T, Burke JA, Wheeler LA. [Characteristic of brimonidine tartrate ophthalmic solution (AIPHAGAN 0.1\%)]. Igaku to Yakugaku. 2012; 67(4):547-555. Japanese.

27. Kaneko E, Wada T, Minagawa Y, Inoue Y. [Pharmacological profile and clinical efficacy of brimonidine tartrate (AIPHAGAN ${ }^{\circledR}$ ophthalmic solution 0.1\%)]. Nihon Yakurigaku Zasshi. 2012;140(4):177-182. Japanese.

28. Rahman MQ, Ramaesh K, Montgomery DM. Brimonidine for glaucoma. Expert Opin Drug Saf. 2010;9(3):483-491.

29. Derck RJ. Adrenergic agonist medications: basic mechanisms. J Glaucoma. 1995;4 Suppl 1:S1-S7.

30. Burke J, Schwartz M. Preclinical evaluation of brimonidine. Surv Ophthalmol. 1996;41 Suppl 1:S9-S18.

31. Araie M, Yamazaki Y, Sugiyama K, Kuwayama Y, Tanihara H. Longterm safety and efficacy of brimonidine ophthalmic solution in patents with primary open angle glaucoma or ocular hypertension. Atarashii Ganka (Journal of the Eye). 2012;29(5):679-686.
Clinical Ophthalmology

\section{Publish your work in this journal}

Clinical Ophthalmology is an international, peer-reviewed journal covering all subspecialties within ophthalmology. Key topics include: Optometry; Visual science; Pharmacology and drug therapy in eye diseases; Basic Sciences; Primary and Secondary eye care; Patient Safety and Quality of Care Improvements. This journal is indexed on

Submit your manuscript here: http://www.dovepress.com/clinical-ophthalmology-journal

\section{Dovepress}

PubMed Central and CAS, and is the official journal of The Society of Clinical Ophthalmology (SCO). The manuscript management system is completely online and includes a very quick and fair peer-review system, which is all easy to use. Visit http://www.dovepress.com/ testimonials.php to read real quotes from published authors. 